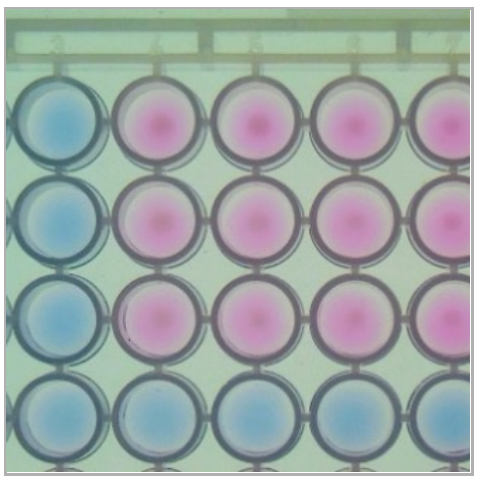

VERSION 3

FEB 09, 2020

\section{open access}

\section{DOI:}

dx.doi.org/10.17504/protocol s.io. $8 \times \mathrm{mhxk} 6$

Protocol Citation: Germán Alberto Téllez Ramírez, Lily Johanna Toro, Juliana Franco Castrillon, Diana Carolina Henao, Jhon Carlos Castaño Osorio, Grupo De Inmunología Molecular GYMOL Universidad Del Quindio 2020. MICRODILUCIÓN EN PLACA PARA LA EVALUACIÓN DE LA ACTIVIDAD ANTIMICROBIANA EN 50 uL . protocols.io

https://dx.doi.org/10.17504/p rotocols.io. $8 \times \mathrm{mhxk6}$

\title{
(3) MICRO-DILUCIÓN EN PLACA PARA LA EVALUACIÓN DE LA ACTIVIDAD ANTIMICROBIANA EN 50 uL V.3
}

\author{
Germán Alberto Téllez Ramírez ${ }^{1}$, Lily Johanna Toro², \\ Juliana Franco Castrillon ${ }^{3}$, Diana Carolina Henao ${ }^{1}$, \\ Jhon Carlos Castaño Osorio ${ }^{3}$,
} Grupo De Inmunología Molecular GYMOL Universidad Del Quindio 3

${ }^{1}$ Centro de Investigaciones Biomédicas;

${ }^{2}$ Centro de Investigaciones Biomédicas - Universidad del Quindío; ${ }^{3}$ Centro de Investigaciones Biomédicas - Universidad del Quindío Colombia

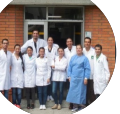

Grupo De Inmunología Molecular GYMOL Universidad Del Quindio Centro de Investigaciones Biomédicas - Universidad del Quind...

\section{ABSTRACT}

Este método es basado en el método clásico de micro-dilución en placa de NCLSS (National Committee of Laboratory Safety and Standards (NCLSS) como fue publicado en Amsterdam, D. 1996. Susceptibility testing of Antimicrobials in liquid media. In 'Antibiotics in Laboratory Medicine', Lorian, V., ed. Fourth Edition, pp.52111. Williams and Wilkins, Baltimore.

Modificado con respecto a la lectura de la placa utilizando un indicador metabólico para incrementar la sensibilidad de la prueba respecto al crecimiento de las bacterias.

La realizacion de este protocolo fue posible gracias al apoyo del departamento administrativo de ciencia tecnología e innovacion, Colciencias a traves del proyecto 111356933173 convocatoria569-2012.

Este protocolo fue estandarizado con el desarrollo del proyecto de grado "OPTIMIZACIÓN DE UN MÉTODO PARA EVALUAR LA ACTIVIDAD ANTIBACTERIANA IN VITRO EN MICROVOLÚMENES" de la estudiante Juliana Franco para optar por el titulo de Biologa. 
MANUSCRIPT CITATION:

- O'Brien J, Wilson I, Orton T, Pognan F. 2000.

Investigation of the Alamar

Blue (resazurin)

fluorescent dye for the

assessment of mammalian

cell cytotoxicity. Eur J

Biochem. 2000 Sep;

267(17):5421-6. Te c h n

i c a I B ulle t in.

CellTiter-Blue ${ }^{\circledR}$ Cell Viability

Assay. Promega.

INSTRUCTIONS FOR USE

OF PRODUCTS G8080,

G8081 AND G8082.

- Wiegand I, Hilpert K, Hancock RE. Agar and broth dilution methods to determine the minimal inhibitory concentration (MIC) of antimicrobial substances. 2007. Nat Protoc. 2008;3(2):163-75. doi:

10.1038/nprot.2007.521.

License: This is an open access protocol distributed under the terms of the Creative Commons Attribution License, which permits unrestricted use, distribution, and reproduction in any medium, provided the original author and source are credited

Protocol status: Working We use this protocol and it's working

Created: Nov 01, 2019

Last Modified: Feb 09, 2020

\section{PROTOCOL integer ID:} 29389

Keywords: antimicrobial, peptides, compounds, fluorescence

\section{GUIDELINES}

El siguiente procedimiento consta del crecimiento de las bacterias, preparacion de la muestra, dilucion de las bacterias, incubacion lectura y analisis.

Tiempo estimado 3 días contando la descongelación de las bacterias.

La lectura se puede realizar por turbidez, Absorbancia libre o con resazurin; o fluorecencia de resorufin.

\section{MATERIALS}

\section{MATERIALS}

$\& 8$ resazurin Acros Organics Catalog \# 189900050

\&8 96-well microtiter plates polypropilene greiner bio-one Catalog \#650201

88 Mueller Hinton scharlau Catalog \#02-136

\section{SAFETY WARNINGS}

(1) Maneje todas las normas de bioseguridad microbiológica dependiendo de la muestra y la bacteria a utilizar (cepas de referencia, aislados clínicos, patogénicos).

\section{BEFORE START INSTRUCTIONS}

Medio de cultivo Muller Hinton líquido (15mL por placa aprox)

Medio de cultivo Mueller Hinton Agar (1 plato por bacteria a evaluar)

Resazurin $440 \mu \mathrm{M}(10 \mathrm{X})$ : tome $0.011 \mathrm{~g}$ de resazurin y lleve a $100 \mathrm{~mL}$ en agua destilada, mezcle en frasco ámbar, filtre por $0.22 \mu \mathrm{m}$ y guarde oculto de la luz $4^{\circ} \mathrm{C}$. (absorbancia máxima resazurin $=603 \mathrm{~nm}$; absorbancia máxima resorufin $=570 \mathrm{~nm}$ ) (excitación 579/Emisión 584)

Antibiótico como control positivo. (Antibiótico antimicótico de cultivo celular 100X= penicilina 10000 unidades $/ \mathrm{ml}$ streptomicina 10000 unidades $/ \mathrm{mL}$ )

Muestras péptido a evaluar para compuestos puros generalmente se trabajan desde concentraciones finales de $100 \mu \mathrm{g} / \mathrm{mL}$.

\section{Preparación de las bacterias}

1 Tome las bacterias a evaluar del banco de células y siga el protocolo de descongelación (siembre en placas de medio selectivo e incube a $37^{\circ} \mathrm{C}$ por $12-24$ horas) 
Inocule una de las colonias de las bacterias a evaluar en tubos conicos de $15 \mathrm{ml}$ con de $2-5 \mathrm{ml}$ de caldo de cultivo Muller Hinton y lleve a $37^{\circ} \mathrm{C}$ en agitación a $180 \mathrm{rpm}$ deje crecer por 5-8 horas aprox.

\section{(2) 12:00:00 incuba bacterias}

\section{(3) 05:00:00 crecimiento inóculo}

\section{Preparación de la muestra}

2 Diluya el péptido a una concentración 10 veces más alta con respecto a la concentración máxima a evaluar (solución stock del péptido).

Realice diluciones seriadas de la solución stock del péptido en agua estéril o medio de cultivo, según corresponda a las diluciones del péptido que se quieren evaluar.

Adicione $5 \mu \mathrm{L}$ de cada una de las diluciones del péptido en cada uno de los pozos correspondientes (columnas 1-10).

Adicione $50 \mu \mathrm{L}$ de medio Mueller Hinton a la columan 11 como control de medio y $45 \mu \mathrm{L}$ a las filas D y $\mathrm{G}$ como control de esterilidad del compuesto.

\section{0:40:00 por placa}

\section{Dilución de las bacterias}

3 Tome las bacterias crecidas en el paso 1 y diluya o deje crecer hasta alcanzar una concentración aproximada de 3-6 por 10 a la 8 UFC, lo cual corresponde a una densidad óptica (O.D) de 0,2 a 0,4 a una longitud de onda de $600 \mathrm{~nm}$ en celda de $1 \mathrm{~cm}$ ó a una O.D de 0,1 a $570 \mathrm{~nm}$ en $100 \mu \mathrm{L}$ en placa de ELISA de 96 pozos.

Tome las bacterias del paso anterior y diluya 1:1000 en medio líquido Muller Hinton para llevar a una concentración de 3-5 por 10 a la 5 UFC (solución de trabajo de bacterias)

Adicione $45 \mu \mathrm{L}$ de la solución de trabajo de bacterias a todos los pozos de la placa de microtitulación menos fila $\mathrm{D}, \mathrm{H}$ y columna 11 como se indica en la Tabla 1.

Tabla 1

\begin{tabular}{|l|l|l|l|l|l|l|l|l|l|l|l|l|l|}
\hline$\mu \mathrm{g} / \mathrm{ml}$ & & 250 & 125 & 62,5 & $\begin{array}{l}31,2 \\
5\end{array}$ & $\begin{array}{l}15,6 \\
2\end{array}$ & 7,81 & 3,91 & 1,95 & 0,98 & 0,49 & $\mathrm{C}-$ & $\mathrm{C}+$ \\
\hline Replicas & & 1 & 2 & 3 & 4 & 5 & 6 & 7 & 8 & 9 & 10 & 11 & 12 \\
\hline $\begin{array}{l}\text { Replica 1 de } \\
\text { cada } \\
\text { tratamiento }\end{array}$ & $\mathrm{A}$ & & & & & & & & & & & & \\
\hline
\end{tabular}




\begin{tabular}{|l|l|l|l|l|l|l|l|l|l|l|l|l|l|}
\hline $\begin{array}{l}\text { Replica 2 de } \\
\text { cada } \\
\text { tratamiento }\end{array}$ & B & & & & & & & & & & & & \\
\hline $\begin{array}{l}\text { Replica 3 de } \\
\text { cada } \\
\text { tratamiento }\end{array}$ & C & & & & & & & & & & & & \\
\hline $\begin{array}{l}\text { Ctrl esterilidad } \\
\text { péptidos }\end{array}$ & $\mathrm{D}$ & & & & & & & & & & & & \\
\hline $\begin{array}{l}\text { Replica 1 de } \\
\text { cada } \\
\text { tratamiento }\end{array}$ & $\mathrm{E}$ & & & & & & & & & & & & \\
\hline $\begin{array}{l}\text { Replica 2 de } \\
\text { cada } \\
\text { tratamiento }\end{array}$ & $\mathrm{F}$ & & & & & & & & & & & & \\
\hline $\begin{array}{l}\text { Replica 3 de } \\
\text { cada } \\
\text { tratamiento }\end{array}$ & $\mathrm{G}$ & & & & & & & & & & & & \\
\hline $\begin{array}{l}\text { Ctrl esterilidad } \\
\text { péptidos }\end{array}$ & & & & & & & & & & & & & \\
\hline
\end{tabular}

Deje incubar por $12-16$ horas (crítico: no más de 16 horas) a $37^{\circ} \mathrm{C}$ sin agitación.

\section{(3) $00: 30: 00$ adicionar bacterias}

\section{(2) 13:00:00 incubación placa}

\section{Análisis}

4 Para leer por turbidimetria lea la absorbancia a 570nm

5 Para leer por Absorbancia con resazurina: adicione $5 \mu \mathrm{L}$ de solución de rezasurina a $440 \mu \mathrm{M}$ para una concentración final de $44 \mu \mathrm{M}$ en cada pozo

Incube por 2 horas a $37^{\circ} \mathrm{C}$

Lea las placas en espectrofotómetro a 570 y $603 \mathrm{~nm}$

Realizar delta: por cada pozo reste la absorbancia de 570nm menos $603 \mathrm{~nm}$ Delta $=$ A570nm-A603nm

\section{A partir del grupo de datos del delta calcula:}

Blancos: calcula la mediana del grupo de blancos C- (medio de cultivo).

Blanco = Mediana (11A:11C)

Reste el blanco a los valores del delta de cada pozo 
A partir del grupo de datos del delta menos el blanco calcula:

Creminiento de bacterias: calcula la mediana del grupo de crecimiento de bacterias $\mathrm{C}+$.

ControlBacterias= Mediana(12A:12C)

A partir de estos valores calcula el porcentaje de crecimiento de cada pozo haciendo una relacion directa.

$\%$ Crecimiento $=(\mathrm{X} /$ Control de bacterias $) \star 100$

$\mathrm{X}=$ Valor de delta menos el blanco de cada pozo.

6 Para leer por Fluorescencia

Adicione resazurina a concentración final de $44 \mu \mathrm{M}$.

Deje incubar por 90 minutos

Lea la placa ext/emisión 579/584 (filtros ext 565/10; em 600/40)

Tome los valores de fluorescencia y calcula:

Blancos: calcula la mediana del grupo de blancos C- (medio de cultivo).

Blanco $=$ Mediana (11A:11C)

Resta el valor del blanco a todos lo pozos.

Crecimiento de bacterias: calcula la mediana del grupo de crecimiento de bacterias $\mathrm{C}+$. ControlBacterias $=$ Mediana(12A:12C)

A partir de estos valores calcula el porcentaje de crecimiento de cada pozo haciendo una relacion directa.

$\%$ Crecimiento $=(\mathrm{X} /$ Control de bacterias $) \star 100$

$\mathrm{X}=$ Valor fluorescencia menos el blanco 


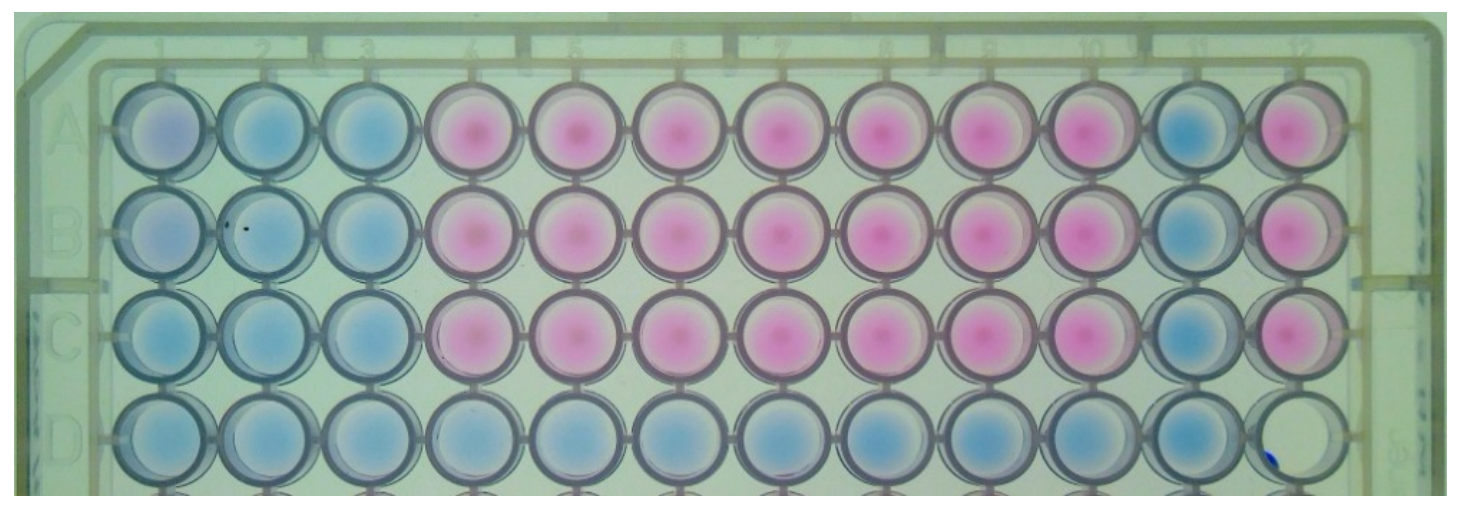

Fig 1. Microdilución en placa de 96 pozos después de 2 horas de incubación con la resazurina. Columnas $1 \mathrm{~A}-1 \mathrm{C}$ a $10 \mathrm{~A}-10 \mathrm{C}$ (molecula a evaluar, desde la concentración más alta $(100 \mathrm{ug} / \mathrm{mL}$ ) hasta $(0,19 \mathrm{ug} / \mathrm{mL})$. Columnas $11 \mathrm{~A}-11 \mathrm{C}$ (control de esterilidad del medio), columnas $12 \mathrm{~A}-12 \mathrm{C}$ (control de viabilidad bacteriana). fila D1-D12 (control de esterilidad de la molecula evaluada)

\section{Dataset}

\section{Microdilución}

NAME

https://drive.google.com/file/d/OB6V_ooAEAQZQMU1VVXY2RXI5Z0U/view?usp=sharing LINK

\section{CBM}

8 Para calcular la concentración bactericida mínima (C.B.M)

Tome $10 \mu \mathrm{L}$ de hasta 3 concentraciones por triplicado sin crecimiento viable y siembre en platos de agar mueller Hinton.

Incube por 18 a $24 \mathrm{~h}$ a $37^{\circ} \mathrm{C}$ y cuente las colonias

La C.B.M es considerada como la concentración más baja que previene la formación de colonias residuales (fig 2 ) 


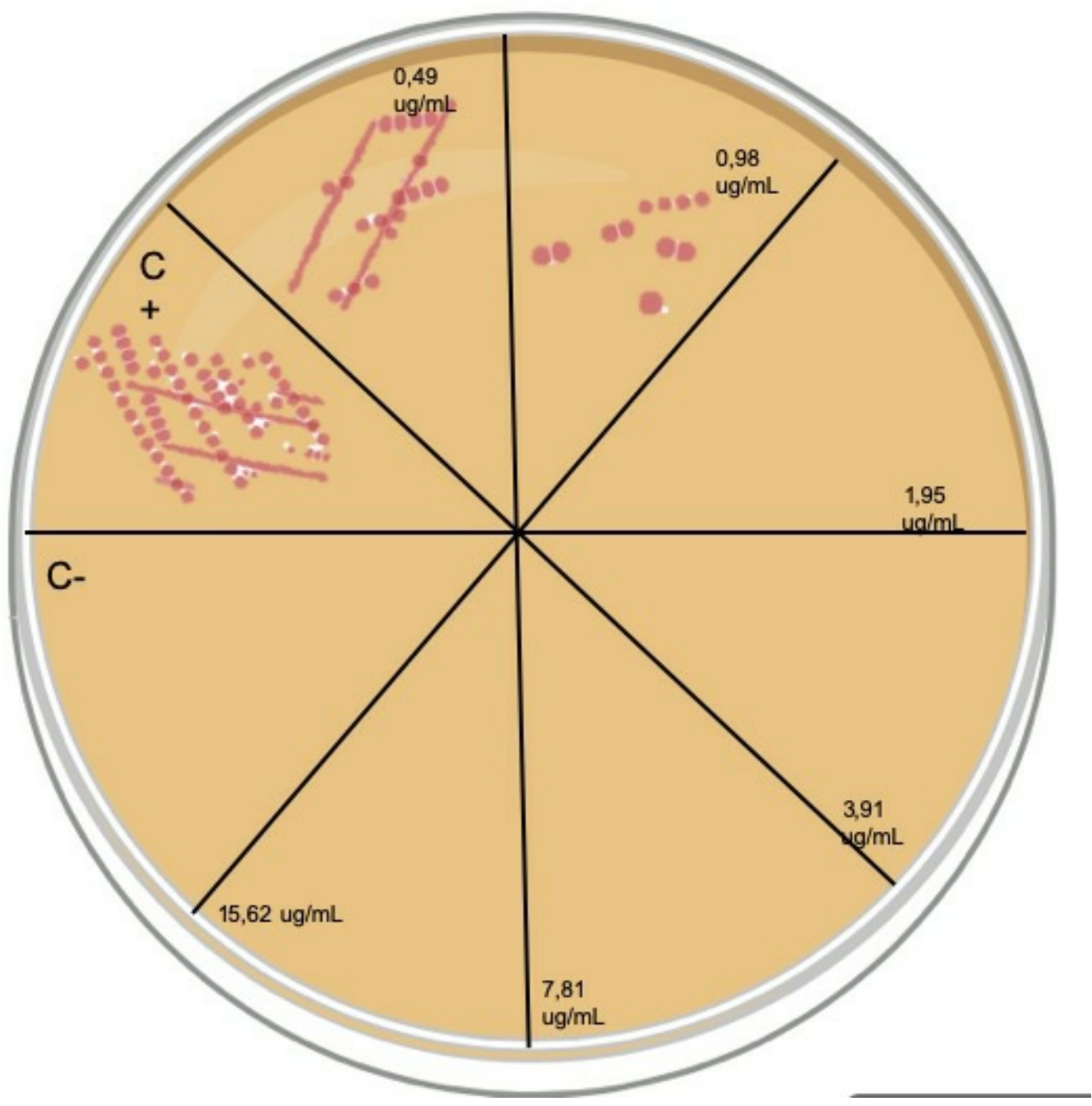

Figura 2. Caja de petri con agar Muller Hinton, en donde la concentración bactericina minima (CMB) es $1,95 \mathrm{ug} / \mathrm{mL}$. 